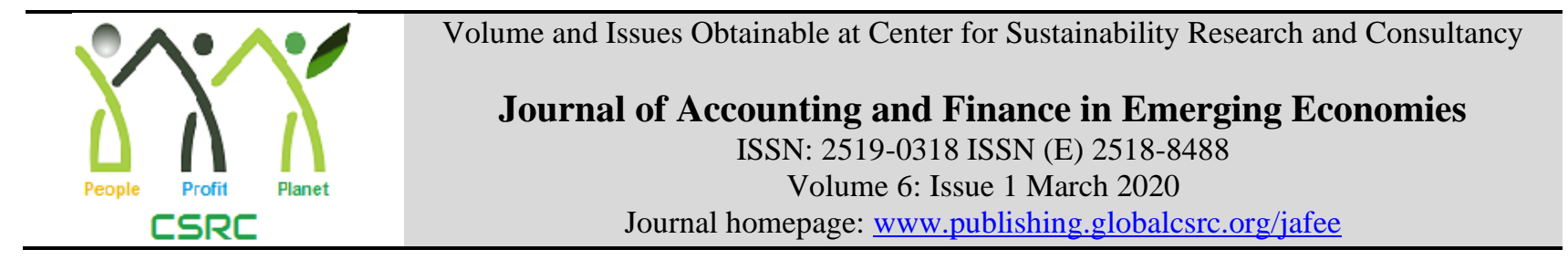

\title{
Knowledge Sharing Culture Influences on Organizational Commitment: The Mediating Role of Pay Satisfaction
}

\author{
${ }^{1}$ Naveed Farooq, ${ }^{2}$ Kauser Hayat, ${ }^{3}$ Hazrat Bilal, ${ }^{4}$ Wahid Raza \\ ${ }^{1}$ Assistant Professor, Institute of Business Studies and Leadership Abdul Wali Khan University, Mardan, Pakistan: \\ Naveedfarooq151@gmail.com \\ ${ }^{2}$ Assistant Professor, Shaheed Zulfiqar Ali Bhatto Institute of Science and Technology (SZABIST) Islamabad, \\ Pakistan: dr.kauser@szabist-isb.edu.pk \\ ${ }^{3}$ Assistant Professor, Center for Management and Commerce University of Swat, Swat, Pakistan: \\ hbilal@uswat.edu.pk \\ ${ }^{4}$ Assistant Professor, Government College of Management Sciences Wana South Waziristan, Tribal District, \\ Pakistan :wrkhattak287@yahoo.com
}

\begin{tabular}{l}
\multicolumn{1}{c}{ ARTICLE DETAILS } \\
\hline History \\
Revised format: February 2020 \\
Available Online: March 2020 \\
\\
\hline Keywords \\
Knowledge Sharing, \\
Organizational Commitment, Pay \\
Satisfaction, Public Sector \\
University
\end{tabular}

JEL Classification: D83, D89,D23

\section{ABSTRACT}

Public sector universities are preliminary knowledge intensive and to stunt their information effective knowledge sharing among faculty is required. We focus on the faculty of public sector universities that share or limit knowledge sharing. Determining which factors promote, influence or impede sharing of knowledge in institutions constitute important avenues for exploration. This paper has focused on three such influences; "knowledge sharing" "organizational commitment" and "pay satisfaction". In this regard, a conceptual model is developed in which pay satisfaction serves as mediator between knowledge sharing (KS) and organizational commitment (OC) among faculty members. Data determining the above mentioned variables is collected from 309 faculty members through standardized questionnaires. Data analysis reveals that KS has positive impact on OC and on Pay Satisfaction (PS). Furthermore, pay satisfaction mediates the relationship between KS and OC. This study recommends a KS culture and pay satisfaction of faculty to maintain and enhance level of commitment among faculty. As KS enable better and faster decision making, reduces the loss of know-how, enhances level of commitment and stimulate innovation and growth.

\section{OPEN ACCESS}

(C) 2020 The authors, under a Creative Commons Attribution-Non

Commercial 4.0

Corresponding author's email address: hbilal@uswat.edu.pk

Recommended citation: Farooq, N., Hayat, K., Bilal, H. \& Raza, W., (2020). Knowledge Sharing Culture Influences on Organizational Commitment: The Mediating Role of Pay Satisfaction. Journal of Accounting and Finance in Emerging Economies, 6 (1), 117-126

DOI: $10.26710 /$ jafee.v6i1.1062

\section{Introduction}

In the knowledge base economy Knowledge Sharing (KS) is viewed critical for institutional effectiveness. It is argued that KS stimulates the performance of both public and private sector employees (Amayah, 
2013). KS has gained importance in organizations (Fein and hesterly, 2007). Recently, in knowledge incentive economy an existing organization's knowledge is fetching important resources. Thus "resource base theory" considered knowledge as one of the most key strategic resource (Van Den Hooff \& De Ridder, 2004). Hansen, Nohria, and Tierney (1999) earlier elaborate that the efficient utilization of this resource is a challenge for institutions. Osterloh and Frey (2000) posit that KS among employees and departments is a critical process.

Determining which factors are significant and assist to promote or hinder KS among university faculty constitute an important avenue for exploration. This study intends to explore two such effects Organizational Commitment (OC) and Pay Satisfactio (PS). OC denotes the loyalty of employees towards their organization (Farooq \& Zia, 2013). Employees who remained in organization due to their emotional attachment show positive conduct, cooperation and sharing of knowledge among stakeholders (Pradhan \& Pradhan, 2015). Dhar (2015) explains that OC contemplate the most imperative notion in the area of organizational behavior. Committed employees do not leave the institution and retaining of such knowledge work force by organization is because of affective commitment like employees voluntarily exchange and contribution towards the institution knowledge pool. Therefore, institutions relying on knowledge workers in businesses need to regulate and enhance the level of commitment through their valuable knowledge sharing (Jayasingam \& Yong, 2013).

Farooq, Ullah, and Zia (2017) argue that pay is an economic value and a return of employees' efforts. Pay pleasure is incredible for motivation and for institutional commitment. Indirectly it helps to achieve organizational goals. Organizations have adopted diverse pay systems to motivate employees for knowledge sharing, improve performance and to get institutional goals. Ba, Stallaert, and Whinston (2001) elaborate that pay satisfaction is very important to facilitate knowledge sharing through formal pay system.

Therefore, this investigation aims to address the issue of KS with OC and to explore the mediating role of PS among the faculty of public sector universities. Jayasingam and Yong (2013) conjure that several studies have investigated diverse factors which influence the level of OC and specifically addresses different level of knowledge work at a micro level. The focus of this research is not only limited to knowledge sharing culture influence but intended to address the mediating position of PS between KS and OC.

\section{Literature Review}

\subsection{Knowledge Sharing Process}

Knowledge Sharing and transfer are synonymously use and consider to have overlapping content. KS refers to the exchange of knowledge amongst individuals, within and between groups, institutional units and organisations, may be oriented or fragmented, but it does not typically have an a priori clear objective. (Paulin, 2015). It is the dissemination and sharing of skills, thoughts, experiences and technology among each other in organization (Wang, Ahmed,\& Rafiq, 2008). It is a procedure where employees jointly exchange their information and mutually generate novel knowledge. Such mutual exchange is critical in interpreting individual knowledge to institutional knowledge. This process involves both "donating", means bringing and "getting", refer to collecting knowledge. Donating knowledge transfers intellectual capital from one person to another, while collecting knowledge involves consulting peers to share knowledge with peers. Hence, both the courses are vigorous- either energetically shared to colleague what one discern or acquire what they discern (Van Den Hooff \& De Ridder, 2004).

Previous studies regarding the influences of KS has recognized numbers of variables from " hard issue" for instance technologies and equipment (Hlupic, Pouloudi,\& Rzevski, 2002) to "soft issue" for example motivation (Kosonen, Gan, Vanhala,\& Blomqvist, 2014), learning orientation (Matzler \& Mueller, 
2011), team innovativeness (Liu \& Phillips, 2011), organizational culture (Lee, Shiue,\& Chen, 2016), job satisfaction (Tong, Tak,\& Wong, 2015), enterprise social network sites (Ellison, Gibbs,\& Weber, 2015). In line with Hlupic et al. (2002) this paper plan to study the soft side of KS, related to both individual and organization.

\subsection{Knowledge Sharing and Organizational Commitment}

Yalabik, Van Rossenberg, Kinnie, and Swart (2015) argue that commitment is a multi-facet perception. It is a force which binds employees for a specific action relevant to institutional goals. OC elaborate the relationship between individual and organization. Researchers has identified three types of commitment (Meyer and Allen 1997): affective commitment (emotional attachment); continuance commitment (switching cost from institution), and normative commitment (a feeling of obligation to serve with the organization). Employee remains committed to his/his supervisor, job, organization or peer. In general knowledge workers are considered more loyal to their profession and less committed to the organization (Jayasingam \& Yong, 2013).

Organizations follow a number of strategies to encourage their workers to be more committed and loyal to their corporate objectives, thereby generating mutual benefits, increasing organizational performance through the knowledge sharing culture. (Han, Chiang,\& Chang, 2010). Committed employees shares four organizational features such as sharing of information, knowledge, rewards and decision-making power and hence improve overall organizational performance (Bowen \& Lawler III, 1992).

Prior investigations found that committed employees induce the essence of altruism (Podsakoff et al. 2000). According to Vandewalle, Van Dyne, and Kostova (1995), psychological ownership influence altruistic spirit over OC which encourages KS behavior. Hislop (2003) also documented that OC anticipate employee's knowledge sharing behavior. Jayasingam and Yong (2013) elaborated that it is important to keep knowledge workers committed and to ensure that institutions may not lose these workers.

Hall (2001) conjure that employees share their knowledge when they are appreciated and ensure that there their knowledge is actually uses. Hinds and Pfeffer (2003) documented that various motivational aspects affects knowledge sharing included organizational individual behaviors. Committed workforce who trust on both management and on peers share their knowledge. Jarvenpaa and Staples (2001) stated that "Greater commitment may engender beliefs that the organizations has rights to the information and knowledge one has created or acquired". To conclude it is likely that knowledge giving and gathering has relation with OC.

Scholars have studied the connection between KS and OC (Hislop, 2002; Van Den Hooff \& De Ridder, 2004; Jo \& Joo, 2011; Casimir, Lee\& Loon, 2012). In the same vein, Kelloway and Barling (2000) found that affective commitment influence organizational performance. Based on the reciprocal relation employees' offer competencies to organization in exchange of pay. Smith and Mckeen (2002) also documented a positive relation between KS and OC. The above studies lead us that KS is important for $\mathrm{OC}$, as OC effects both willingness to contribute and willingness to collect knowledge. Therefore, this paper aims to check the impact of KS on OC among the faculty members of public sector universities of KPK.

\subsection{Pay Satisfaction and Knowledge Sharing}

Bartol and Srivastava (2002) posited that organizations use compensation to encourage employees for knowledge sharing. It ranges from monetary incentive for instance bonus to non-monetary reward like dinner or certificate. Literature revealed mix results of pay satisfaction with knowledge sharing. Carleton (2011) found inverse relationship of pay satisfaction with knowledge sharing. The author argued that 
knowledge workers incline to personal growth rather than pay satisfaction. However, some studies found that a good pay structure stimulate knowledge sharing (Forstenlechner \& Lettice, 2007). Horwitz, Heng, and Quazi (2003) documented that performance incentives, bonuses and attractive pay plan retained knowledge workforce. Knowledge workers quit organization due to poor pay and job dissatisfaction. Pay satisfaction is influential motivator (Walker \& Yip, 2018), inducing knowledge workers' behavior (Lin and Tseng 2005; Forstenlechner and Lettice 2007). Keeping in view the above discussion the following hypotheses are developed.

H1: KS has significant impact on OC.

H2: KS has significant impact on pay satisfaction.

H3: Pay satisfaction meditates the relationship between KS and OC.

\section{Methodology}

The current study is survey based, cross sectional, correlational, regression, mediating and quantitative investigation of universities faculty.

\subsection{Sample and Data Collection}

The population of this enquiry is the faculty members serving in public sector universities of Khyber Pakhtunkhwa. There are total 4039 faculty members (Hayat, Jan and Nadeem, 2017), all the faculty members represent the population.

We spread our survey questionnaires to 410 participants employed in Basic Pay Scale (BPS) and in Tenure Track System (TTS). BPS is a widely used pay scale by almost all public sector institutions which differentiate the level of pay (Pakistan-Hotline, 2012). TTS is alternative salary scheme initiated in 2002 for the faculty. The intention of this scheme is to enhance the performance of faculty (Khan \& Jabeen, 2011). In response 309 useable questionnaires were returned, yielding a response rate of 75 percent. Average age of the respondents were 36 years (SD_15.18), consisting 76\% male and 24\% female. Among the respondents $20 \%$ hold $\mathrm{PhD}$ degree, $75 \%$ faculty are having M.Phil. degree and only 5\% are having Master degree. The mean tenure was 11.83 (SD_10.13), years. When approaching our respondents, they were assure that the data will be used for the research purposes only and confidentiality will be emphasized. Simple random sampling technique was used to collect data regarding the knowledge sharing, pay satisfaction and organizational commitment among faculty.

\subsection{Measures}

The research instruments for this study were structured questionnaires adopted from the literature, based on a Likert- Scale to measure KS, PS and OC. To measure knowledge sharing of employees a ten items scale was used. This scale measure knowledge donating and knowledge collecting and have used in different organizations (Van Den Hooff \& De Ridder, 2004). The level of PS was assessed through Heneman III and Schwab (1985) pay satisfaction questionnaire (PSQ). This is a twenty items scale, universal instrument which measure various dimensions of PS (Heneman \& Judge, 2000; Sturman \& Short, 2000). A sample item is "Size of my current salary." To measure the level of organizational commitment a twelve items scale of Meyer, Allen, and Smith (1993) was used. 


\section{Data Analysis and Results}

\begin{tabular}{|l|l|l|l|l|l|l|l|}
\hline \multicolumn{7}{|c|}{ Table 1 Means, Standard deviations, Coefficient Alphas, and Correlations between Variables } \\
\hline & Variables & M & SD & 1 & 2 & 3 \\
\hline 1 & Knowledge sharing & 4.81 & 0.76 & $(0.74)$ & & \\
\hline 2 & Organizational commitment & 3.97 & 0.51 & $0.58^{* *}$ & $(0.79)$ & \\
\hline 3 & Pay satisfaction & 4.53 & 0.63 & $0.57 * *$ & $0.73^{* *}$ & $(0.71)$ \\
\hline
\end{tabular}

$\mathrm{N}=309$; Cronbach Alpha in parenthesis

** Correlation is significant at the 0.01 level (2-tailed).

Table 1 above demonstrates the means, standard deviations, coefficient alphas and correlations between variables of the research. It explain that knowledge sharing is correlated with $\mathrm{OC}(\mathrm{r}=0.58, \mathrm{p}<0.01)$, with pay satisfaction $(r=0.57, \mathrm{p}<0.01)$ and the correlation between $\mathrm{OC}$ and pay satisfaction is $(\mathrm{r}=0.73, \mathrm{p}<$ $0.01)$. These values give preliminary support to the anticipated hypotheses.

The table also explains the reliability via Cronbach Alpha values of the variables of the study.

Cronbach Alpha values of KS, OC and PS is $0.74,0.79$, and 0.71 respectively. All these values are above 0.7 signifying that the data is consistent internally. Hair, Black, Babin, Anderson, \& Tatham, (1998) also conjure the same interpretation. However, Flynn et al. (1990) recommend the value ranging from 0.895 to 0.946 is also acceptable. Hence, all sub-scales reveal well over the lowest adequate reliability level of 0.7 .

\subsection{Regression and Mediation Analysis through Baron and Kenny (1986)}

The mediation analysis of the knowledge sharing, OC and pay satisfaction is checked by regression analysis recommend by Baron and Kenny (1986). The results are shown in the Table 2 given below.

Table 2. Simple Regression Analysis

\begin{tabular}{|l|c|c|c|c|c|c|}
\hline & & & & & & \\
\hline Predictor & $\beta$ & R2 & Adj R2 & F & t & P \\
\hline KS $\rightarrow$ OC & 0.50 & .254 & .251 & 101.39 & 10.06 & 0.000 \\
\hline $\begin{array}{l}\text { KS } \rightarrow \text { PS } \\
\text { PS OC }\end{array}$ & & .339 & & 152.72 & 12.35 & \\
\hline
\end{tabular}

\subsection{KS (Knowledge sharing), OC (Organizational Commitment), PS (Pay Satisfaction)}

Regression analysis elaborates the relationship of variables. The table explains that knowledge sharing has significant effect on OC. The $t$ value is above 2 means that KS has found noteworthy influence on the OC. The $\beta$ is 0.50 that explains that a one unit variation in KS carries about 0.50 unit changes in OC. Knowledge sharing has got significance effect on pay satisfaction. The value of $t$ is 12.35 which is above 2 , means that KS has influences on PS. The value of $\beta$ is 0.58 that explains that a one unit change in KS conveys about 0.58 unit changes in PS. Similarly, PS has strong impact on the level of OC. The value of $t$ is above 26.32 and the value of beta is 0.83 signify that a 1 unit change in PS bring .83 unit change in the 
level of OC. All the values are in acceptable range of significance for conducting meditation analysis.

Table 3 The impact of both KS and PS on OC.

\begin{tabular}{|c|c|c|c|c|c|c|}
\hline & & OC & & & & \\
\hline Predictor & $\beta$ & $\mathrm{R} 2$ & Adj R2 & $\mathrm{F}$ & $\mathrm{t}$ & $\mathrm{P}$ \\
\hline $\mathrm{KS}$ & 0.026 & 0.504 & 0.254 & 101.39 & .660 & .510 \\
\hline PS & 0.82 & 0.836 & 0.669 & 693.120 & 21.00 & 000 \\
\hline
\end{tabular}

The results of table 3 demonstrates the last step of mediating effect of KS and PS with OC. The table shows and provide evidence the significant effects of KS and PS on OC. When both (KS \& PS) were regress together the value of beta fall to 0.026 from 0.50 and the $t$ value decreases from 10.06 to 0.66. Similarly, the value of PS fall to 0.82 from 0.83 and the t value decreases to 21.00 from 26.32. It explicate that pay satisfaction has observed knowledge sharing and has substantial impact on OC.

\subsection{Preacher and Hayes (2004) Bootstrapping Technique of Mediation}

To give more robustness to this investigation Preacher and Hayes (2004) bootstrapping technique of mediation was also performed. As compare to Baron and Kenny (1986) this test is considered superior and Sobel test. According to (Preacher \& Hayes, 2004), if zero is not included in the 95\% CI for indirect effect, mediation is determined. Below in table 3 the mediation analysis results are presented.

Table4. Mediating Regression Analysis through Preacher and Hayes Bootstrapping Technique

\begin{tabular}{|l|l|l|l|l|l|}
\hline \multirow{2}{*}{ Path } & Total effect & $\begin{array}{l}\text { Direct } \\
\text { effect }\end{array}$ & \multirow{2}{*}{$\begin{array}{l}\text { Indirect } \\
\text { effect }\end{array}$} & \multicolumn{2}{|l|}{ 95\% CI } \\
\cline { 4 - 6 } & & Lower level & High level \\
\hline KS $\rightarrow$ PS $\rightarrow$ OC & 0.52 & 0.027 & 0.50 & 0.38 & 0.62 \\
\hline
\end{tabular}

The above table explains that the direct effect of knowledge sharing on organizational commitment was $(.027, \mathrm{p}<.01)$ and the indirect effect via pay satisfaction was significant $(.50, \mathrm{p}<.01,95 \% \mathrm{CI}=0.38$, HI 0.62). The standardized total (direct and indirect) result of (KS) on (OC) was found 0.52 , that is because both direct (unmediated) and indirect (mediated) effect of pay satisfaction on OC, when pay satisfaction increases by 1 standard deviation, $\mathrm{OC}$ increases by 0.52 standard deviations. The current result indicated that $\mathrm{H} 3$ of the research study was supported and confirmed that pay satisfaction mediates the relationship between knowledge sharing and OC.

\section{Discussion}

The main impetus of this enquiry was to verify the argument of growing realization that knowledge sharing within institutions is critical process, effecting diverse factors. The study found a positive connection of KS with OC. Roodbari, (2016) conjured the same positive association of KS with OC. Joo (2010) elaborated that highest level of OC is align with KS. Van Den Hooff and De Ridder (2004) found that knowledge sharing influence OC. Cabrera, Collins, and Salgado (2006) also argued that OC is related to KS. In the same vein, Joo (2010) found the same significance relationship of knowledge sharing with OC. The research investigated that knowledge sharing has positive relation with pay satisfaction. Jayasingam and Yong (2013) conjured the same positive linkages. Furthermore, the study found a positive relation of pay satisfaction with OC. Nawab and Bhatti (2011) explored the same relationship among the educational institutes of Pakistan. 
Lastly, the investigation confirm the mediating consequence of pay satisfaction between KS and OC and bridges the gap in literature of knowledge sharing, pay satisfaction and perceived organizational commitment in a single model.

\section{Implications}

Recently universities are operating in an increasing complex and in turbulent surrounding. To meet the challenges of the competitive academic environment flexibility, information sharing and openness are getting critically important for the survival of academia. Faculty is the most imperative resources, especially with universities in the hunt of a justifiable competitive advantage. This study suggest that universities should not be made a places of employment but seats of learning, research and repository of knowledge and innovation. The public sector higher education institutions are required to monitor its pay system, as pay satisfaction is significance in bridging KS with OC. The results of the current study suggest that pay satisfaction observed KS and have strong influence on the level of OC. Currently, HEC has demand 85 billion rupees whereas government has provided 68 billion rupees indicating that it is difficult for universities to enhance the level of commitment through pay satisfaction. Hence, supporting and knowledge sharing environment is the last resort to enhance the level of commitment and to retain expertise in universities. With respect to the hypothetical contribution, this exploration has linked organizational learning, public policy and organizational commitment research with each other's. Joo (2010) also argued that OC entails efforts on both the institutional (organizational learning culture) and group (employees) levels.

\section{References}

Ba, Sulin, Stallaert, Jan, \& Whinston, Andrew B. (2001). Research commentary: introducing a third dimension in information systems design - the case for incentive alignment. Information systems research, 12(3), 225239.

Baron, Reuben M, \& Kenny, David A. (1986). The moderator-mediator variable distinction in social psychological research: Conceptual, strategic, and statistical considerations. Journal of personality and social psychology, 51(6), 1173.

Bartol, Kathryn M, \& Srivastava, Abhishek. (2002). Encouraging knowledge sharing: The role of organizational reward systems. Journal of Leadership \& Organizational Studies, 9(1), 64-76.

Bowen, David E, \& Lawler III, Edward E. (1992). The empowerment of service workers: What, why, how, and when. MIT Sloan Management Review, 33(3), 31.

Cabrera, Angel, Collins, William C, \& Salgado, Jesus F. (2006). Determinants of individual engagement in knowledge sharing. The International Journal of Human Resource Management, 17(2), 245-264.

Carleton, Karen. (2011). How to motivate and retain knowledge workers in organizations: A review of the literature. International Journal of Management, 28(2), 459.

Casimir, Gian, Lee, Karen, \& Loon, Mark. (2012). Knowledge sharing: influences of trust, commitment and cost. Journal of knowledge management, 16(5), 740-753.

Dhar, Rajib Lochan. (2015). Service quality and the training of employees: The mediating role of organizational commitment. Tourism management, 46, 419-430.

Ellison, Nicole B, Gibbs, Jennifer L, \& Weber, Matthew S. (2015). The use of enterprise social network sites for knowledge sharing in distributed organizations: The role of organizational affordances. American Behavioral Scientist, 59(1), 103-123.

Farooq, Naveed, Ullah, Raza, \& Zia, Yorid Ahsan. (2017). Pay Disparity among Employees of the Federal Government of Pakistan and the Mediating Role of Motivation between Pay Satisfaction and Organizational Citizenship Behavior. FWU Journal of Social Sciences, 11(2), 60-70.

Farooq, Naveed, \& Zia, Yorid Ahsan. (2013). Gender and Organizational Commitment. Putaj Humanities \& Social Sciences, 20.

Flynn, Barbara B, Sakakibara, Sadao, Schroeder, Roger G, Bates, Kimberly A, \& Flynn, E James. (1990). 
Empirical research methods in operations management. Journal of operations management, 9(2), 250-284. Forstenlechner, Ingo, \& Lettice, Fiona. (2007). Cultural differences in motivating global knowledge workers. Equal Opportunities International, 26(8), 823-833.

Han, Tzu-Shian, Chiang, Hsu-Hsin, \& Chang, Aihwa. (2010). Employee participation in decision making, psychological ownership and knowledge sharing: mediating role of organizational commitment in Taiwanese high-tech organizations. The International Journal of Human Resource Management, 21(12), 2218-2233.

Hansen, Morten T, Nohria, Nitin, \& Tierney, Thomas. (1999). What's your strategy for managing knowledge. The knowledge management yearbook 2000-2001, 1-10.

Heneman, HG, \& Judge, TA. (2000). Incentives and motivation. Compensation in organizations: Progress and prospects, 61-103.

Heneman III, Herbert G, \& Schwab, Donald P. (1985). Pay satisfaction: Its multidimensional nature and measurement. International journal of Psychology, 20(2), 129-141.

Hinds, Pamela J, \& Pfeffer, Jeffrey. (2003). Why organizations don't "know what they know": Cognitive and motivational factors affecting the transfer of expertise. Sharing expertise: Beyond knowledge management, 3-26.

Hislop, Donald. (2003). Linking human resource management and knowledge management via commitment: A review and research agenda. Employee relations, 25(2), 182-202.

Hislop, Donald. (2002). Mission impossible? Communicating and sharing knowledge via information technology. Journal of Information Technology, 17(3), 165-177.

Hlupic, Vlatka, Pouloudi, Athanasia, \& Rzevski, George. (2002). Towards an integrated approach to knowledge management:'hard','soft'and 'abstract'issues. Knowledge and process management, 9(2), 90-102.

Horwitz, Frank M, Heng, Chan Teng, \& Quazi, Hesan Ahmed. (2003). Finders, keepers? Attracting, motivating and retaining knowledge workers. Human resource management journal, 13(4), 23-44.

Jarvenpaa, Sirkka L, \& Staples, D Sandy. (2001). Exploring perceptions of organizational ownership of information and expertise. Journal of Management Information Systems, 18(1), 151-183.

Jayasingam, Sharmila, \& Yong, Jing Ren. (2013). Affective commitment among knowledge workers: The role of pay satisfaction and organization career management. The International Journal of Human Resource Management, 24(20), 3903-3920.

Jo, Sung Jun, \& Joo, Baek-Kyoo. (2011). Knowledge sharing: The influences of learning organization culture, organizational commitment, and organizational citizenship behaviors. Journal of Leadership \& Organizational Studies, 18(3), 353-364.

Joo, Baek-Kyoo. (2010). Organizational commitment for knowledge workers: The roles of perceived organizational learning culture, leader-member exchange quality, and turnover intention. Human resource development quarterly, 21(1), 69-85.

Kelloway, E Kelvin, \& Barling, Julian. (2000). Knowledge work as organizational behavior. International journal of management reviews, 2(3), 287-304.

Khan, Tayyeb Ali, \& Jabeen, Nasira. (2011). Tenure track system in higher education institutions of Pakistan: Prospects and challenges. Educational Research and Reviews, 6(9), 605-621.

Kosonen, Miia, Gan, Chunmei, Vanhala, Mika, \& Blomqvist, Kirsimarja. (2014). User motivation and knowledge sharing in idea crowdsourcing. International Journal of Innovation Management, 18(05), 1450031.

Lee, Jung-Chieh, Shiue, Yih-Chearng, \& Chen, Chung-Yang. (2016). Examining the impacts of organizational culture and top management support of knowledge sharing on the success of software process improvement. Computers in Human Behavior, 54, 462-474.

Liu, Yuwen, \& Phillips, James S. (2011). Examining the antecedents of knowledge sharing in facilitating team innovativeness from a multilevel perspective. International Journal of Information Management, 31(1), 4452.

Matzler, Kurt, \& Mueller, Julia. (2011). Antecedents of knowledge sharing-Examining the influence of learning and performance orientation. Journal of Economic Psychology, 32(3), 317-329. 
Meyer, John P, Allen, Natalie J, \& Smith, Catherine A. (1993). Commitment to organizations and occupations: Extension and test of a three-component conceptualization. Journal of applied psychology, 78(4), 538.

Nawab, Samina, \& Bhatti, Komal Khalid. (2011). Influence of employee compensation on organizational commitment and job satisfaction: A case study of educational sector of Pakistan. International Journal of Business and Social Science, 2(8).

Osterloh, Margit, \& Frey, Bruno S. (2000). Motivation, knowledge transfer, and organizational forms. Organization Science, 11(5), 538-550.

Pakistan-Hotline. (2012). BPS Pay Scales and Salaries of Government Servants in Pakistan. Retrieved March,22, 2016, from http://www.pakistanhotline.com/2011/08/bps-pay-scales-and-salaries-of.html

Pradhan, Sajeet, \& Pradhan, Rabindra Kumar. (2015). An empirical investigation of relationship among transformational leadership, affective organizational commitment and contextual performance. Vision, 19(3), 227-235.

Preacher, Kristopher J, \& Hayes, Andrew F. (2004). SPSS and SAS procedures for estimating indirect effects in simple mediation models. Behavior research methods, 36(4), 717-731.

Sturman, Michael C, \& Short, Jeremy C. (2000). Lump-sum bonus satisfaction: Testing the construct validity of a new pay satisfaction dimension.

Titi Amayah, Angela. (2013). Determinants of knowledge sharing in a public sector organization. Journal of knowledge management, 17(3), 454-471.

Tong, Canon, Tak, Walder Ip Wah, \& Wong, Anthony. (2015). The impact of knowledge sharing on the relationship between organizational culture and job satisfaction: The perception of information communication and technology (ICT) practitioners in Hong Kong. International Journal of Human Resource Studies, 5(1), 19-47.

Van Den Hooff, Bart, \& De Ridder, Jan A. (2004). Knowledge sharing in context: the influence of organizational commitment, communication climate and CMC use on knowledge sharing. Journal of knowledge management, 8(6), 117-130.

Van Dyne, Linn, \& Pierce, Jon L. (2004). Psychological ownership and feelings of possession: Three field studies predicting employee attitudes and organizational citizenship behavior. Journal of Organizational Behavior: The International Journal of Industrial, Occupational and Organizational Psychology and Behavior, 25(4), 439-459.

Vandewalle, Don, Van Dyne, Linn, \& Kostova, Tatiana. (1995). Psychological ownership: An empirical examination of its consequences. Group \& Organization Management, 20(2), 210-226.

Walker, Dayna O, \& Yip, Jeffrey. (2018). Paying it forward? The mixed effects of organizational inducements on executive mentoring. Human Resource Management, 57(5), 1189-1203.

Wang, Catherine L, Ahmed, Pervaiz K, \& Rafiq, Mohammed. (2008). Knowledge management orientation: construct development and empirical validation. European Journal of Information Systems, 17(3), 219-235.

Yalabik, Zeynep Y, Van Rossenberg, Yvonne, Kinnie, Nicholas, \& Swart, Juani. (2015). Engaged and committed? The relationship between work engagement and commitment in professional service firms. The International Journal of Human Resource Management, 26(12), 1602-1621. 
